\title{
Abrupt change of dielectric properties in mullite due to titanium and strontium incorporation by sol-gel method
}

\author{
Biplab Kumar PAUL, Kumaresh HALDAR, Debasis ROY, Biswajoy BAGCHI, \\ Alakananda BHATTACHARYA, Sukhen DAS* \\ Physics Department, Jadavpur University, Kolkata-700 032, India
}

Received: March 24, 2014; Revised: June 16, 2014; Accepted: July 06, 2014

(C) The Author(s) 2014. This article is published with open access at Springerlink.com

\begin{abstract}
Highly crystallized mullite has been achieved at temperatures of $1100{ }^{\circ} \mathrm{C}$ and $1400{ }^{\circ} \mathrm{C}$ by sol-gel technique in presence of titanium and strontium ions of different concentrations: $\mathrm{G}_{0}=0 \mathrm{M}$, $\mathrm{G}_{1}=0.002 \mathrm{M}, \mathrm{G}_{2}=0.01 \mathrm{M}, \mathrm{G}_{3}=0.02 \mathrm{M}, \mathrm{G}_{4}=0.1 \mathrm{M}, \mathrm{G}_{5}=0.2 \mathrm{M}$ and $\mathrm{G}_{6}=0.5 \mathrm{M}$. X-ray diffraction (XRD), Fourier transform infrared spectroscopy (FTIR), field emission scanning electron microscopy (FESEM), LCR meter characterized the samples. Mullite formation was found to depend on the concentration of the ions. The dielectric properties (dielectric constant, loss tangent and AC conductivity) of the composites have been measured, and their variation with increasing frequency and concentration of the doped metals was investigated. All the experiments were performed at room temperature. The composites showed maximum dielectric constants of 24.42 and 37.6 at $1400{ }^{\circ} \mathrm{C}$ of $0.01 \mathrm{M}$ concentration for titanium and strontium ions at $2 \mathrm{MHz}$, respectively. Due to the perfect nature of the doped mullite, it can be used for the fabrication of high charge storing capacitors and also as ceramic capacitors in the pico range.
\end{abstract}

Keywords: mullite; sol-gel technique; X-ray diffraction (XRD); dielectric properties; field emission scanning electron microscopy (FESEM)

\section{Introduction}

Mullite is a promising engineering ceramic material for use in optical, dielectric and structural applications. Mullite has a unique combination of properties, such as high melting point $\left(1830{ }^{\circ} \mathrm{C}\right)$, good electrical resistance, good mechanical strength, low thermal expansion coefficient, high strength and high creep resistance at any temperature range. Mullite is also a leading candidate material for high transmitting IR windows, electronic substrates, humidity sensors, protective

\footnotetext{
* Corresponding author.

E-mail: sdasphysics@gmail.com
}

coatings, electrical insulators and turbine engine components, etc.

Electronic industry is continuously trying to develop processes that are more advanced and lead to forecasting transistor density and chip complexity, and operating speed or frequency for future technological developments $[1,2]$. The main challenge is to carry electric power and distribute clock signals that control the timing and synchronize the operation. This challenge extends beyond the material properties and technology and also involves system architecture [3-7]. Controlled chip connections used in high package density logic devices require a good compatibility of thermal expansion coefficient (TEC) between substrate and Si chip. The mullite composite system has required 
strength and much closer match of TEC with Si chip than alumina.

Several reports have been published dealing with synthesis of mullite composites in presence of various mineralizing agents to improve the mechanical and chemical properties, and also there are some recent publications related to the dielectric properties of these modified mullite composites [8-14]. We have studied the dielectric constant, loss tangent, AC conductivity of the mullite composites doped with varying concentrations of tungsten ions with different frequencies at room temperature. We also have studied the dielectric constant, loss tangent, AC conductivity and magnetization of the mullite composites doped with varying concentrations of iron ions with different frequencies at room temperature. The results indicate that the sample of $0.01 \mathrm{M}$ concentration has the highest dielectric constant 24.42 at frequency $2 \mathrm{MHz}[15,16]$.

\section{Experimental}

\section{1 Sample materials}

Chemicals used in the preparation of mullite precursor gels were aluminium nitrate nonahydrate $\left(\mathrm{Al}\left(\mathrm{NO}_{3}\right)_{3} \cdot 9 \mathrm{H}_{2} \mathrm{O}\right.$, MERCK, India, $99.9 \%$ ), aluminium isopropoxide $\left(\mathrm{Al}(-\mathrm{O}-\mathrm{i}-\mathrm{Pr})_{3}\right.$, puriss, Spectrochem Pvt. Ltd., India), tetraethyl orthosilicate $\left(\mathrm{Si}\left(\mathrm{OC}_{2} \mathrm{H}_{5}\right)_{4}\right.$, TEOS, MERCK, Germany), titanium isopropoxide ( $\mathrm{Ti}\left\{\mathrm{OCH}\left(\mathrm{CH}_{3}\right)_{2}\right\}_{4}, \mathrm{MERCK}$, Germany, 99.9\%) and strontium chloride hexahydrate $\left(\mathrm{SrCl}_{2} \cdot 6 \mathrm{H}_{2} \mathrm{O}\right.$, MERCK, India, 99.9\%).

\section{2 Sample preparation and characterization}

Mullite precursor gel powder was synthesized by dissolving stoichiometric amounts of $\mathrm{Al}(-\mathrm{O}-\mathrm{i}-\mathrm{Pr})_{3}$ and TEOS in $0.5 \mathrm{M}$ solution of $\mathrm{Al}\left(\mathrm{NO}_{3}\right)_{3} \cdot 9 \mathrm{H}_{2} \mathrm{O}[12,13]$. The molar ratio of $\mathrm{Al}(-\mathrm{O}-\mathrm{i}-\mathrm{Pr})_{3}: \mathrm{Al}\left(\mathrm{NO}_{3}\right)_{3} \cdot 9 \mathrm{H}_{2} \mathrm{O}$ was kept at 3.5:1. The molar ratio of $\mathrm{Al}: \mathrm{Si}$ was $3: 1$ $[12,13]$.

For preparation of the doped gels, the titanium and strontium salts were added to the original solution in the ratio of $\mathrm{Al}: \mathrm{Si}: x$, where $x$ is the concentration of the metal salts in molarity. The titanium and strontium salts were added such that in the final solution $x=0.002 \mathrm{M}\left(\mathrm{G}_{1}\right), 0.01 \mathrm{M}\left(\mathrm{G}_{2}\right), 0.02 \mathrm{M}\left(\mathrm{G}_{3}\right), 0.1 \mathrm{M}\left(\mathrm{G}_{4}\right)$, $0.2 \mathrm{M}\left(\mathrm{G}_{5}\right), 0.5 \mathrm{M}\left(\mathrm{G}_{6}\right)[12,13]$. The sol would be in the gel form after vigorous stirring for $5 \mathrm{~h}$, and the sol was maintained overnight at $70{ }^{\circ} \mathrm{C}$. Finally, the gel was dried at $120{ }^{\circ} \mathrm{C}$. The samples were then pelletized and sintered at $1100{ }^{\circ} \mathrm{C}$ and $1400{ }^{\circ} \mathrm{C}$ or $3 \mathrm{~h}$ in a muffle furnace under air atmosphere (heating rate $10{ }^{\circ} \mathrm{C} / \mathrm{min}$ ) $[12,13]$.

\section{3 Instruments used}

The crystalline phases developed in the samples sintered at $1100{ }^{\circ} \mathrm{C}$ and $1400{ }^{\circ} \mathrm{C}$ were analyzed by $\mathrm{X}$-ray powder diffractometer (XRD, model-D8, Bruker AXS, Wisconsin, USA) using $\mathrm{Cu} \mathrm{K} \alpha$ radiation at $1.5418 \AA$ and operating at $40 \mathrm{kV}$ with a scan speed of $1 \mathrm{~s} / \mathrm{step}$.

The characteristic stretching and bending modes of vibration of chemical bonds of a sample can be effectively evaluated by spectroscopic methods. $1 \%$ of the sample was mixed with spectroscopy grade $\mathrm{KBr}$, pelletized to form disc and analyzed by Fourier transform infrared (FTIR) spectroscopy (FTIR-8400S, Shimadzu).

AC parameters such as capacitance (C) and dissipation factor $(\tan \delta)$ of the samples were measured in the frequency range of $20 \mathrm{~Hz}$ to $2 \mathrm{MHz}$ using LCR meter (HP Model 4274 A, Hewlett-Packard, USA). The variation of dielectric constant and loss tangent was studied by recording these parameters using sample pellets of uniform thickness at ten different frequencies from $20 \mathrm{~Hz}$ to $2 \mathrm{MHz}$.

Morphology of the sintered gels was observed by field emission scanning electron microscopy (FESEM, JSM 6700F, JEOL Ltd., Tokyo, Japan). Samples were etched with $25 \% \mathrm{HF}$ solution. About $2 \mathrm{mg}$ of each sample was dispersed in ethanol, and a single drop was placed on copper grid for sample preparation.

\section{Results and discussion}

From the X-ray diffractograms, it can be seen that the undoped sample shows considerable mullite phase at $1100{ }^{\circ} \mathrm{C}$ and $1400{ }^{\circ} \mathrm{C}$, while for the doped samples, prominent mullite peaks are also obtained and changing with the concentrations. Mullite phase (JCPDS No. 150776) increases with increasing concentration of metal ions (Figs. 1 and 2). From the diffractograms, it has been observed that with increase in the concentration of doped titanium and strontium ions, mullite phase in the composites increases. The rutile phase (JCPDS No. 211276) is obtained at $1100{ }^{\circ} \mathrm{C}$ and $1400{ }^{\circ} \mathrm{C}$ for titanium doped mullite. The 

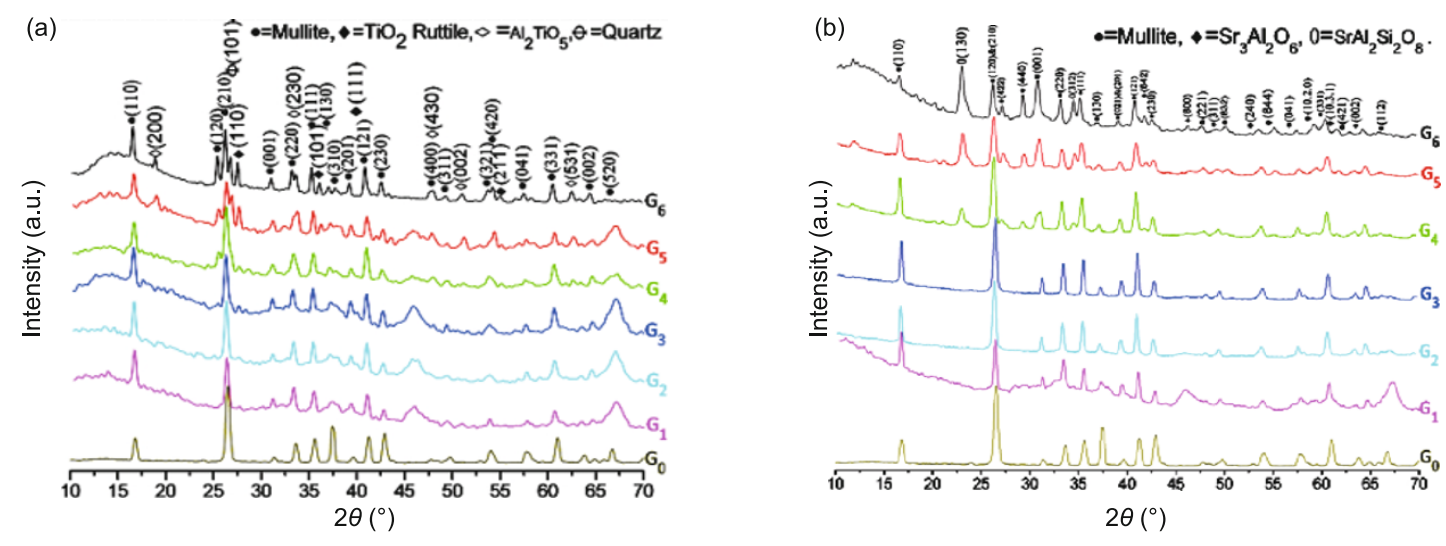

Fig. 1 XRD patterns of (a) titanium and (b) strontium doped mullite precursor gels sintered at $1100{ }^{\circ} \mathrm{C}$ with increasing doping concentration.
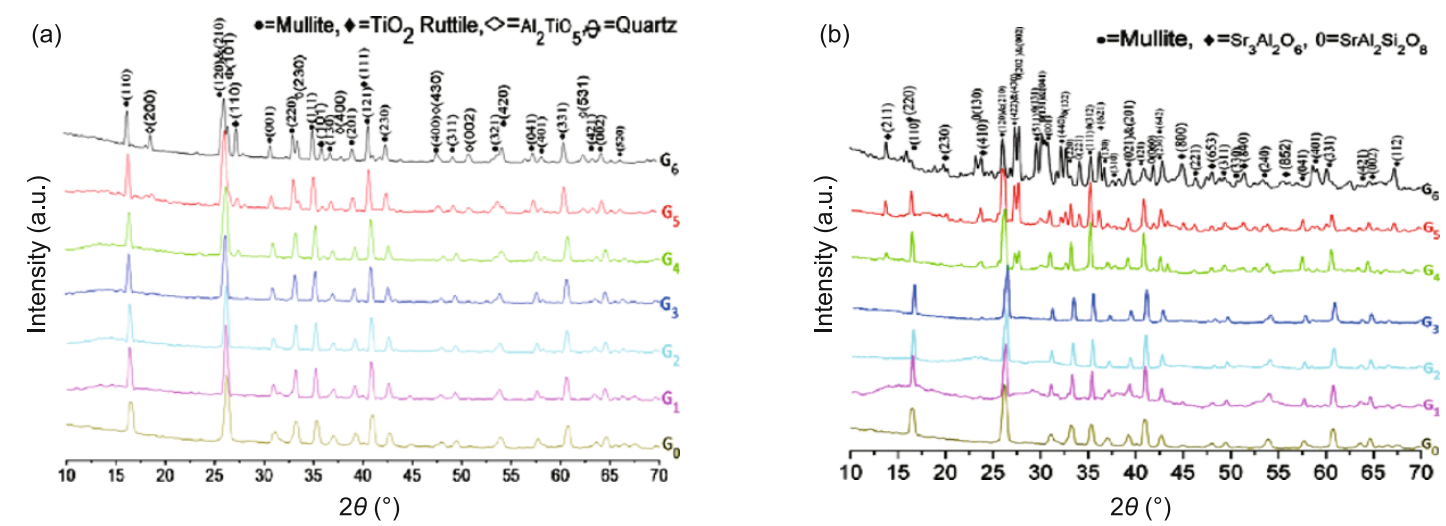

Fig. 2 XRD patterns of (a) titanium and (b) strontium doped mullite precursor gels sintered at $1400{ }^{\circ} \mathrm{C}$ with increasing doping concentration.

diffractograms show that the amount of mullite formation is more in the case of strontium for all concentrations. The hump at the lower scattering angle shows that glass phase increases with the increase of metal ion concentration. Aluminates and oxide phases are also observed in the diffractograms. The phase variation of the composite is due to the changed concentration of each metal ion and John-Teller distortion [12,13]. Interaction of the metal ions with the alumina and silica components of the gels is responsible for the accelerated transformation to mullite phase. The content of crystalline mullite decreases and the background increases due to the increase of metal ion concentration and the formation of metal silicate and aluminate phases of the samples. The "mineralizing" effect continues for samples $\mathrm{G}_{4}$ to $\mathrm{G}_{6}$ with respect to control sample $\mathrm{G}_{0}$. The "mineralizing" effect of transition metals on phase transformation of mullite is well documented in Refs. [8-14]. Probably there are two possibilities, either complete incorporation of metal ions in mullite structure or dissolution of metal ions in the Si-rich glassy phase. Such amorphous phase increases with the increased metal ions, as an account of decrease of the crystalline phases. The densification of the composite may be due to increased consolidation of the composite because of the molten state of the sintered gel at $1400{ }^{\circ} \mathrm{C}$ ((Fig. 11(d)) and for the increasing metal ion concentration.

By spectroscopic method, the characteristic stretching and bending modes of vibration of chemical bonds of a sample can be effectively evaluated. $1 \%$ of the sample is mixed with spectroscopy grade $\mathrm{KBr}$, pelletized to form disc and analyzed by FTIR spectroscopy. Figure 3 shows the FTIR spectra of titanium and strontium doped sintered gels at $1100{ }^{\circ} \mathrm{C}$. Mullite gives characteristic bands at wave numbers around $463 \mathrm{~cm}^{-1}, 542 \mathrm{~cm}^{-1}\left(\mathrm{AlO}_{6}\right), 731 \mathrm{~cm}^{-1}\left(\mathrm{AlO}_{4}\right)$, $828 \mathrm{~cm}^{-1}\left(\mathrm{AlO}_{4}\right), 1074 \mathrm{~cm}^{-1}$ (Si phase), $1130 \mathrm{~cm}^{-1}$ ( $\mathrm{Si}-\mathrm{O}$ stretching mode), $1176 \mathrm{~cm}^{-1}$ and $1368 \mathrm{~cm}^{-1}$ $[13,14]$, and $1226 \mathrm{~cm}^{-1}$ and $1450 \mathrm{~cm}^{-1}$ for rutile at $1100{ }^{\circ} \mathrm{C}$ [15]. Strontium doped mullite gives characteristic bands at wave numbers around $465 \mathrm{~cm}^{-1}$, 

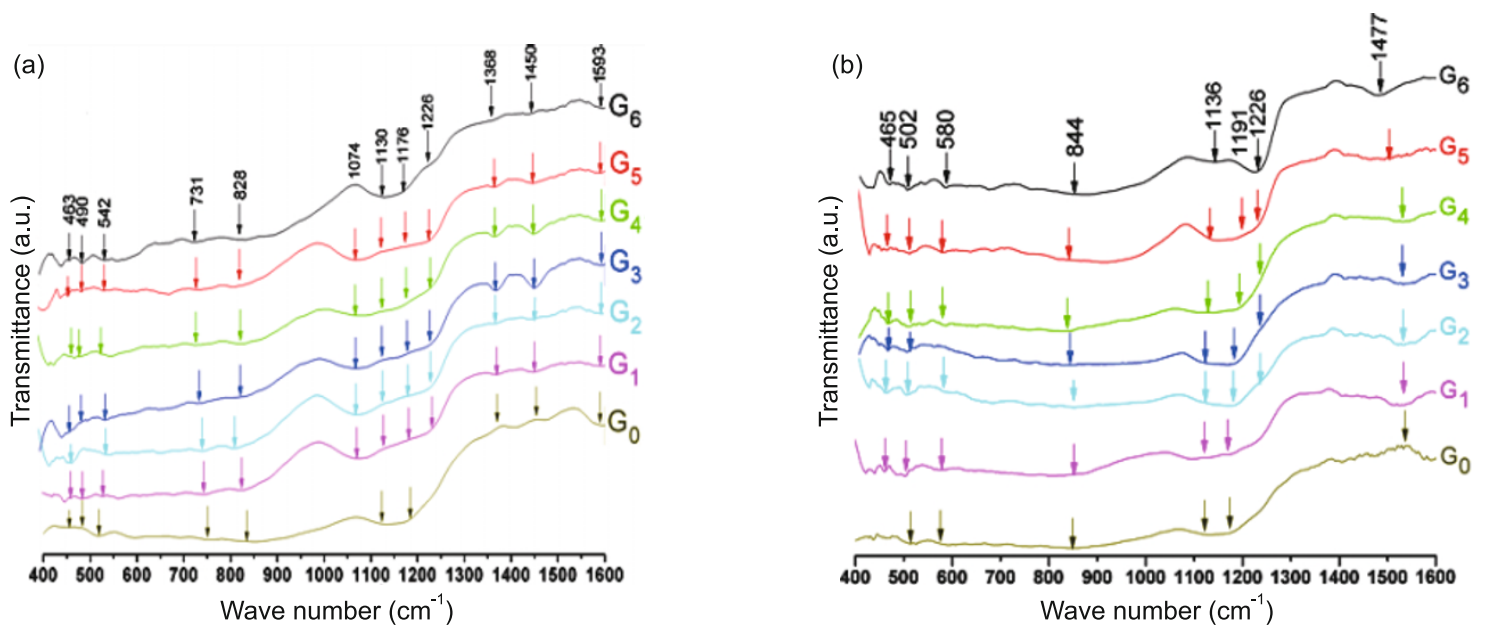

Fig. 3 FTIR patterns in transmittance mode of (a) titanium and (b) strontium doped mullite precursor gels sintered at $1100{ }^{\circ} \mathrm{C}$ with increasing doping concentration.

$502 \mathrm{~cm}^{-1}, 580 \mathrm{~cm}^{-1}\left(\mathrm{AlO}_{6}\right), 844 \mathrm{~cm}^{-1}\left(\mathrm{AlO}_{4}\right)$ and $1136 \mathrm{~cm}^{-1}$ (Si-O stretching mode), and $1191 \mathrm{~cm}^{-1}$ and $1226 \mathrm{~cm}^{-1}$ for mullite, and for strontium aluminates $\left(\mathrm{Sr}_{3} \mathrm{Al}_{2} \mathrm{O}_{6}\right)$ at $1477 \mathrm{~cm}^{-1}$ at $1100{ }^{\circ} \mathrm{C}[16]$.

Figure 4 shows the FTIR spectra of titanium and strontium doped mullite at $1400{ }^{\circ} \mathrm{C}$. Sanad et al. $[10,14,17]$ showed that all the IR spectra obtained for the $\mathrm{Y}^{3+}, \mathrm{Gd}^{3+}$ doped samples are almost similar to the characteristic peaks of pure o-mullite sample in their overall appearance. For titanium at $1400{ }^{\circ} \mathrm{C}$, characteristic bands are obtained at wave numbers around $463 \mathrm{~cm}^{-1}, 509 \mathrm{~cm}^{-1}, 570 \mathrm{~cm}^{-1}\left(\mathrm{AlO}_{6}\right), 740 \mathrm{~cm}^{-1}$ $\left(\mathrm{AlO}_{4}\right), 820 \mathrm{~cm}^{-1}\left(\mathrm{AlO}_{4}\right), 1114 \mathrm{~cm}^{-1}$ ( $\mathrm{Si}-\mathrm{O}$ stretching mode) and $1173 \mathrm{~cm}^{-1}$ [16], and $609 \mathrm{~cm}^{-1}, 1405 \mathrm{~cm}^{-1}$ and $1593 \mathrm{~cm}^{-1}$ for rutile at $1400{ }^{\circ} \mathrm{C}[15,16]$. For strontium at $1400{ }^{\circ} \mathrm{C}$, characteristic bands are obtained

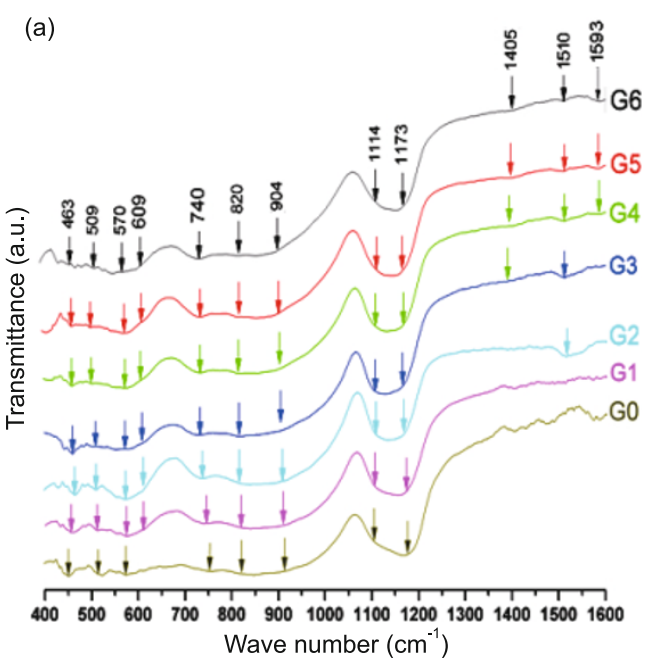

at wave numbers $455 \mathrm{~cm}^{-1}, 613 \mathrm{~cm}^{-1}\left(\mathrm{AlO}_{6}\right), 700 \mathrm{~cm}^{-1}$ $\left(\mathrm{AlO}_{4}\right), 850 \mathrm{~cm}^{-1}\left(\mathrm{AlO}_{4}\right), 950 \mathrm{~cm}^{-1}(\mathrm{Si}-\mathrm{OH}), 1092 \mathrm{~cm}^{-1}$ ( $\mathrm{Si}-\mathrm{O}$ phase), $1152 \mathrm{~cm}^{-1}$ ( $\mathrm{Si}-\mathrm{O}$ stretching mode) and $1526 \mathrm{~cm}^{-1}\left(\mathrm{Sr}_{3} \mathrm{Al}_{2} \mathrm{O}_{6}\right)$.

The dielectric constant or relative permittivity $\left(\varepsilon_{\mathrm{r}}\right)$ of each sample is calculated from the capacitance using the formula:

$$
\varepsilon_{\mathrm{r}}=(C \times d) /\left(A \varepsilon_{0}\right)
$$

where $C$ is the capacitance of the material; $d$ is the thickness of the pellet; $A$ is the area of cross section; and $\varepsilon_{\mathrm{r}}$ and $\varepsilon_{0}$ are the dielectric constant and permittivity of free space, respectively $[18,19]$.

The dielectric properties of materials are used to describe electrical energy storage, dissipation and energy transfer. Electrical storage is the manifestation of dielectric polarization. The variation of dielectric

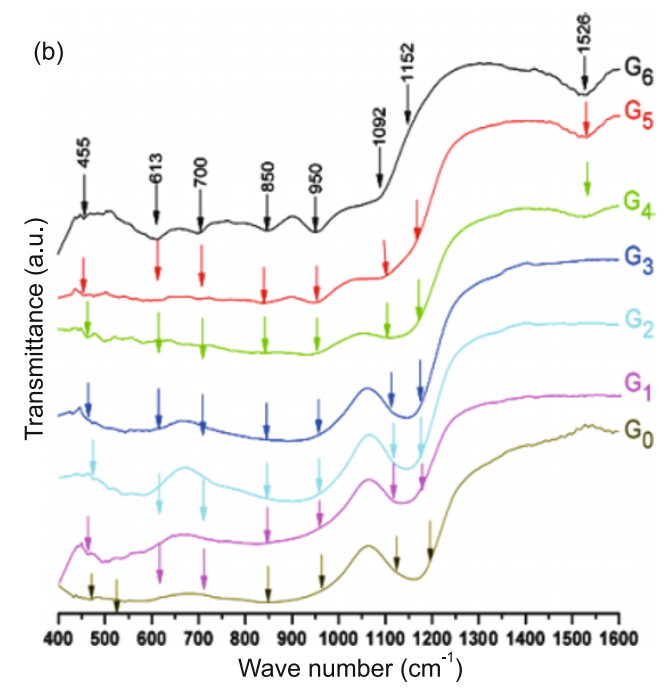

Fig. 4 FTIR patterns in transmittance mode of (a) titanium and (b) strontium doped mullite precursor gels sintered at $1400{ }^{\circ} \mathrm{C}$ with increasing doping concentration. 
constant with frequency of titanium and strontium doped mullite composites at $1100{ }^{\circ} \mathrm{C}$ are shown in Fig. 5 and similarly at $1400{ }^{\circ} \mathrm{C}$ in Fig. 6 . From the plots, it is clear that in all the cases, dielectric constant decreases with increase in frequency and attains a saturation tendency at $2 \mathrm{MHz}$ for each concentration of doped metal. This behavior of dielectric may be explained qualitatively by the supposition of the mechanism of the polarization process in mullitetitanium/strontium. The electron-hopping model [13] can explain the electrical conduction mechanism. It is known that the effect of polarization is to reduce the field inside the medium. Therefore, the dielectric constant of a substance may be decreased substantially as the frequency is increased [20]. The electronic polarizations can orient themselves with the electric field at the lower frequency range, but at higher

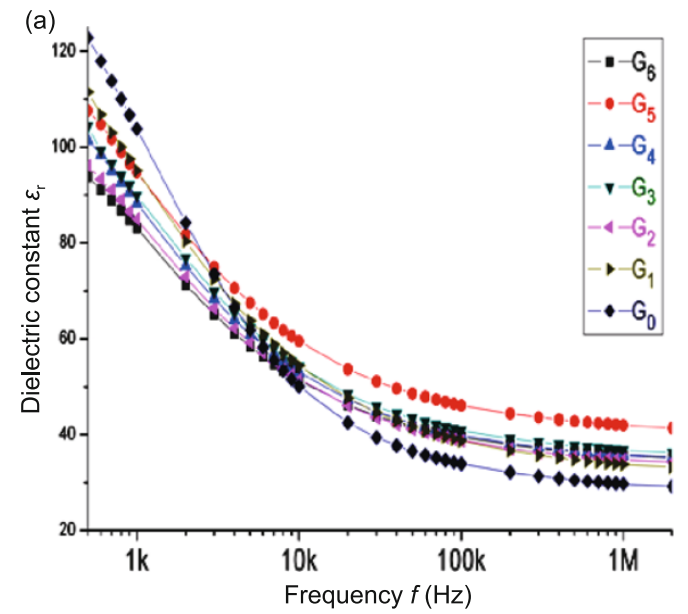

frequency the internal individual dipoles contributing to the dielectric constant cannot move instantly. So as frequency of an applied voltage increases, the dipole response is limited and the dielectric constant diminishes [21,22]. The drop in resistivity with frequency predicts the presence of glassy phase /amorphous phase in the mullite structure that may increase the mobility of the ions such as $\mathrm{Ti}^{4+} / \mathrm{Sr}^{2+}$ and $\mathrm{Al}^{3+}$ which find an easy path to move and hence increase the electrical conductivity. Moreover, it is known that the incorporation of transition metals in the periodic lattice of the mullite crystal structure helps in attending a lower band structure [11,14]. The dielectric results of Sanad et al.'s data are in good agreements with the data shown at $1100{ }^{\circ} \mathrm{C}$ and $1400{ }^{\circ} \mathrm{C}$ of $0.01 \mathrm{M}$ concentration for titanium and strontium ions in the $\mathrm{MHz}$ frequency region $[10,14,17]$.

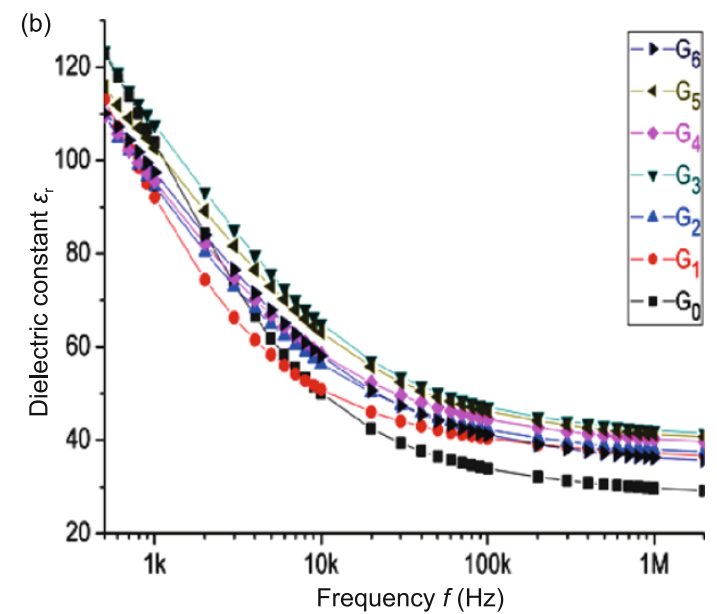

Fig. 5 Frequency response dielectric constant behavior of (a) titanium and (b) strontium doped mullite precursor gels sintered at $1100{ }^{\circ} \mathrm{C}$ with increasing doping concentration.
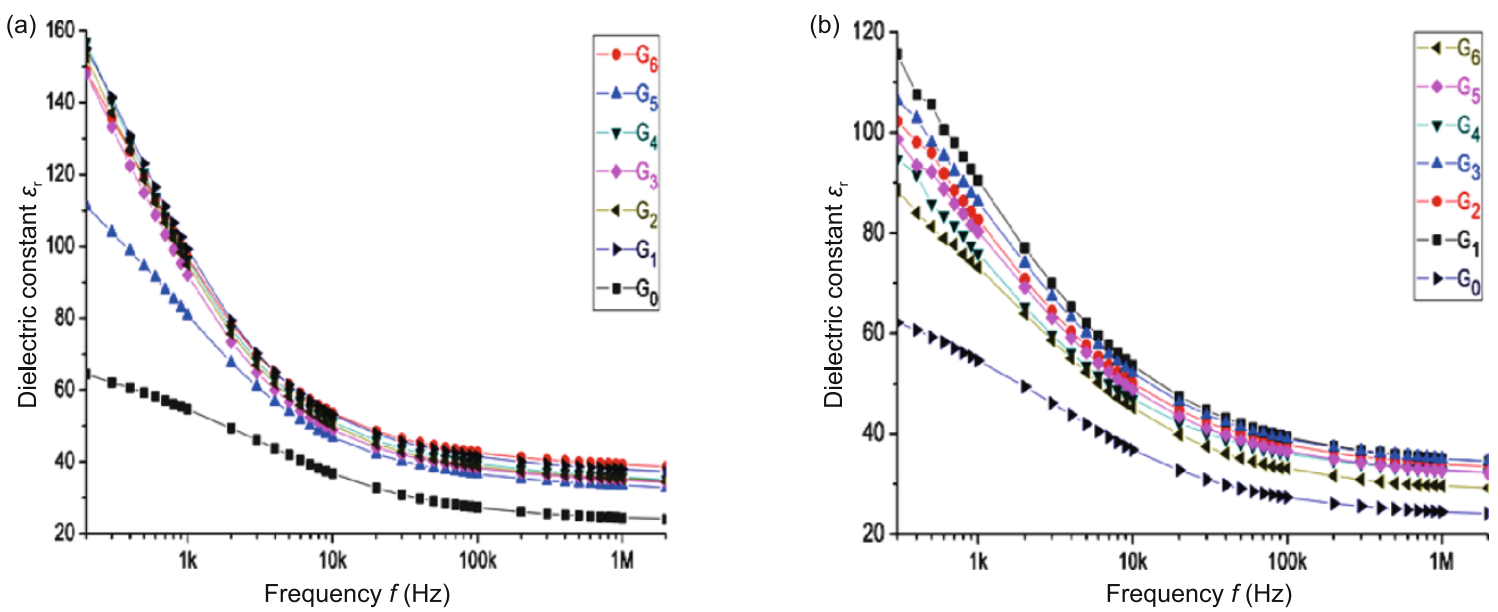

Fig. 6 Frequency response dielectric constant behavior of (a) titanium and (b) strontium doped mullite precursor gels sintered at $1400{ }^{\circ} \mathrm{C}$ with increasing doping concentration. 
The dielectric loss $(\tan \delta)$ of all samples is measured in the frequency range of $20 \mathrm{~Hz}$ to $2 \mathrm{MHz}$ in the room temperature and is graphically shown in Figs. 7 and 8 for $1100{ }^{\circ} \mathrm{C}$ and $1400{ }^{\circ} \mathrm{C}$, respectively. It is found that for all samples, $\tan \delta$ decreases with increasing frequency and reaches constant value at $2 \mathrm{MHz}$, but initially it increases until $10 \mathrm{kHz}$. Dissipation factor initially increases maybe due to the greater electronic polarization of the metal ions and also due to the formation of the metal aluminates and oxides. After $10 \mathrm{kHz}$, the internal electric field will be responsible for the decrement of the dissipation factor. The electronic polarizations can orient themselves with the electric field at the lower frequency range, but at higher frequency, the internal individual dipoles contributing to the dielectric constant cannot move instantly. So as the frequency of an applied voltage

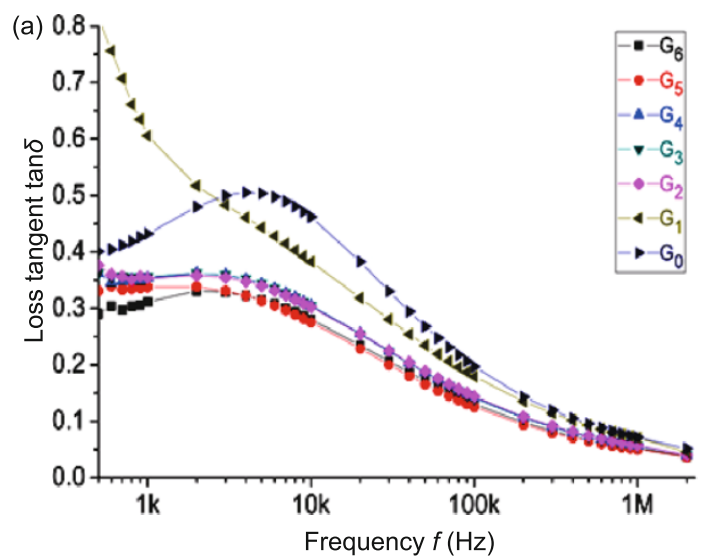

increases, the dipole response is limited and the dielectric constant diminishes, and similarly the dielectric loss $\tan \delta$ decreases.

$\mathrm{AC}$ conductivity of the samples is then calculated using the formula:

$$
\sigma_{\mathrm{AC}}=2 \pi f \tan \delta \varepsilon_{\mathrm{r}} \varepsilon_{0}
$$

where $f$ is the frequency in $\mathrm{Hz}$; $\tan \delta$ is the dielectric loss factor; and $\varepsilon_{\mathrm{r}}$ and $\varepsilon_{0}$ are the dielectric constant of the material and permittivity of free space, respectively $[23,24]$.

In $\sigma_{\mathrm{AC}}$ vs. $f$ graphs, a linear increment of $\mathrm{AC}$ conductivity with frequency for all doping concentrations is observed for $1100{ }^{\circ} \mathrm{C}$ (Fig. 9) and $1400{ }^{\circ} \mathrm{C}$ (Fig. 10). It has been observed that the increment of $\mathrm{AC}$ conductivity suddenly jumps from $\mathrm{G}_{4}$ to $\mathrm{G}_{5}$. The linearity of the plots follows the frequency

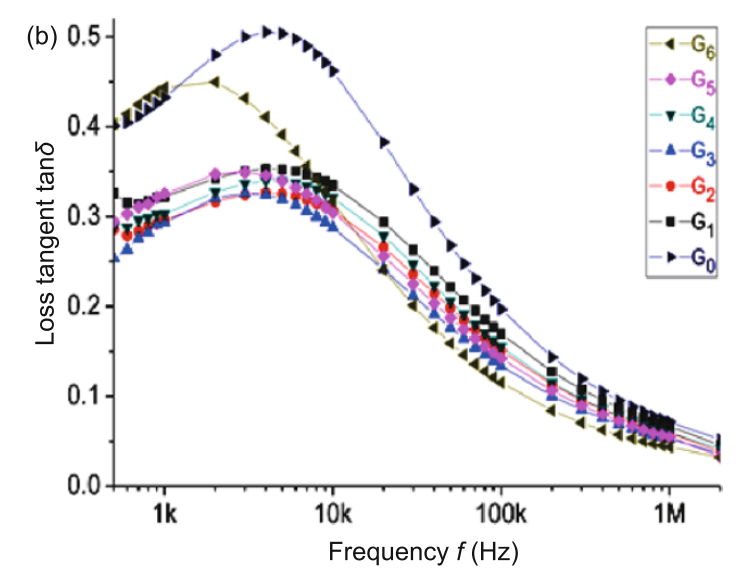

Fig. 7 Frequency response loss tangent behavior of (a) titanium and (b) strontium doped mullite precursor gels sintered at $1100{ }^{\circ} \mathrm{C}$ with increasing doping concentration.
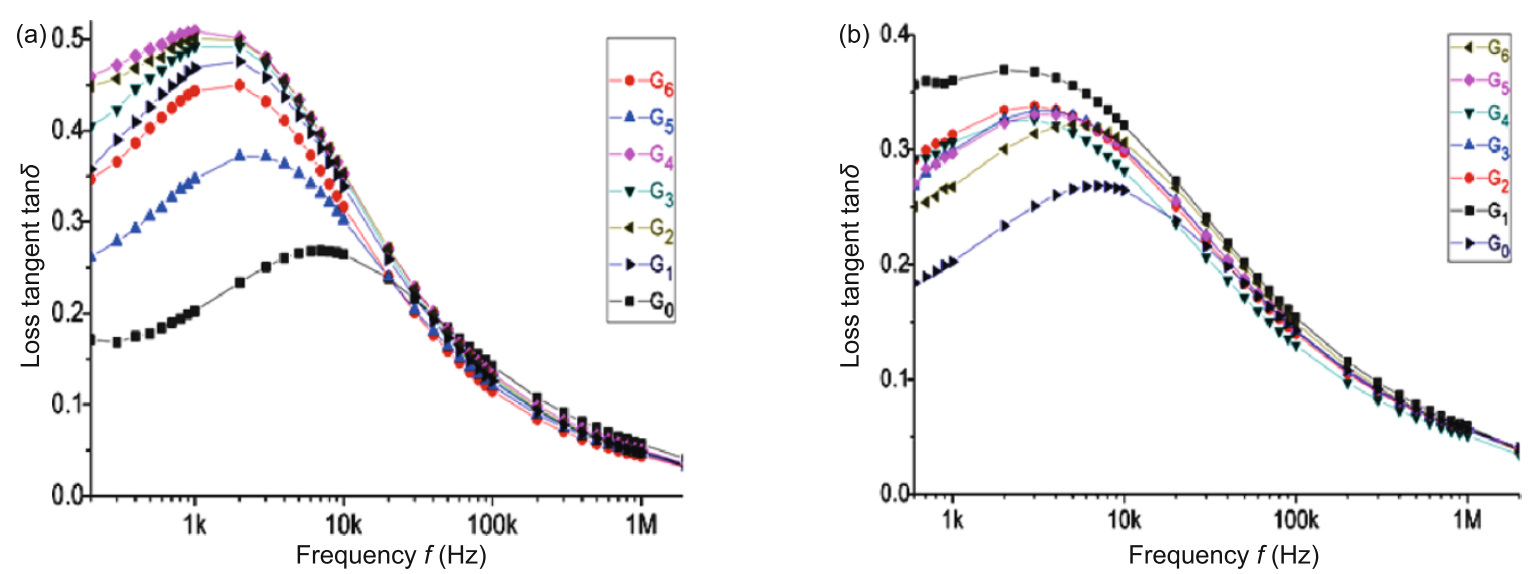

Fig. 8 Frequency response loss tangent behavior of (a) titanium and (b) strontium doped mullite precursor gels sintered at $1400{ }^{\circ} \mathrm{C}$ with increasing doping concentration. 

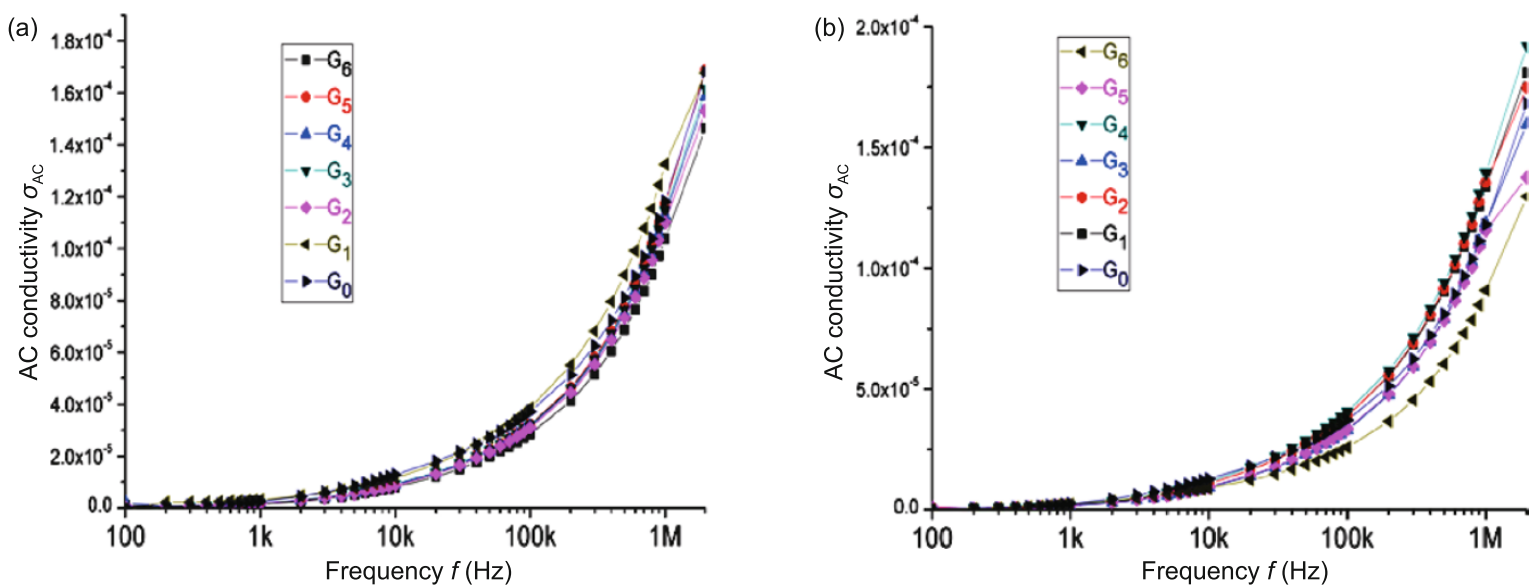

Fig. 9 Frequency response AC conductivity behavior of (a) titanium and (b) strontium doped mullite precursor gels sintered at $1100{ }^{\circ} \mathrm{C}$ with increasing doping concentration.
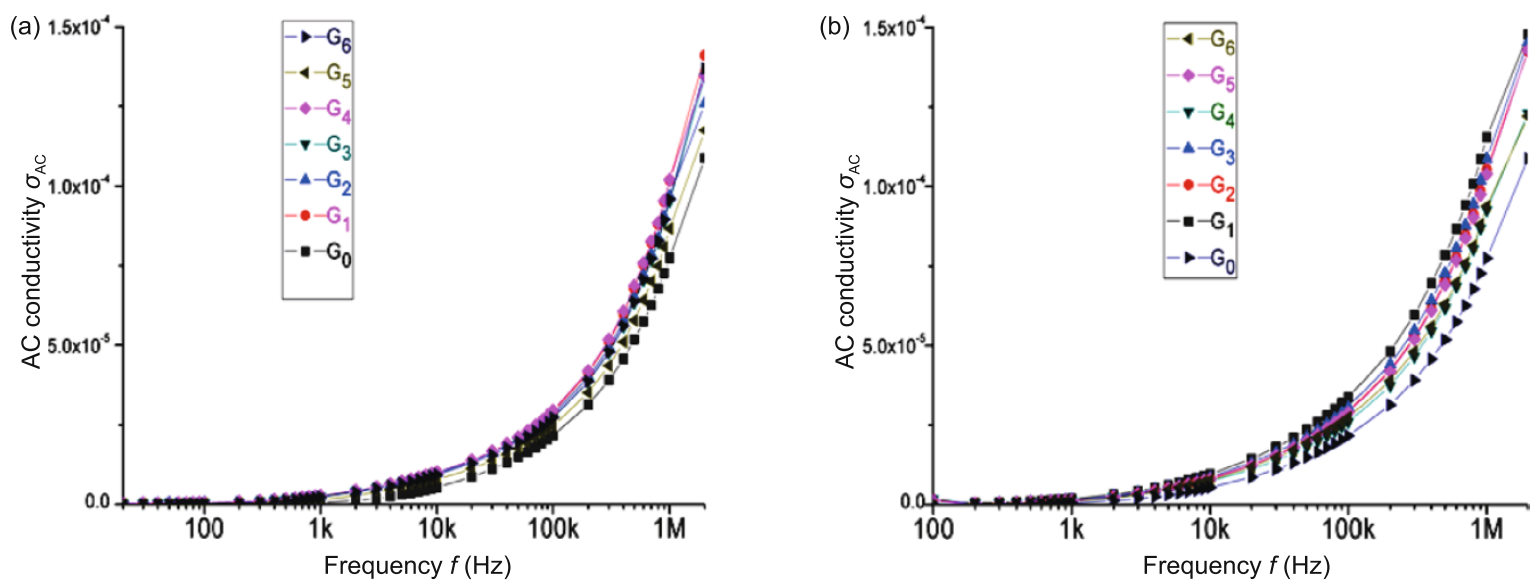

Fig. 10 Frequency response AC conductivity behavior of (a) titanium and (b) strontium doped mullite precursor gels sintered at $1400{ }^{\circ} \mathrm{C}$ with increasing doping concentration.

dependent part of Jonscher's universal power law which can be represented by the equation:

$$
\sigma(\omega)=\sigma_{\mathrm{DC}}+\sigma_{0} \omega^{s}
$$

where $\sigma_{\mathrm{DC}}$ is the $\mathrm{DC}$ (or frequency independent) conductivity; $\quad \sigma_{0}$ is a temperature dependent parameter; and $s$ lies in the range of $0<s<1$ [20-25].

The morphology of the mullite particles with $\mathrm{G}_{3}$ concentration of the doped metal was investigated by FESEM. $G_{3}$ sample shows titanium doped mullite nanoparticles of size $50 \mathrm{~nm}$ at $1100{ }^{\circ} \mathrm{C}$ and $100 \mathrm{~nm}$ at $1400{ }^{\circ} \mathrm{C}$ [25]. Similarly for strontium doped mullite, distinct elongated morphology of mullite particles of size $3 \mu \mathrm{m}$ is embedded in the matrix (Fig. 11). The change in morphology of the sample is due to the combined effect of the doped metals and the sintering temperature. The particles in the case of strontium doped mullite take the shape of whiskers at $1400{ }^{\circ} \mathrm{C}$ due to the "mineralizing" effect of $\mathrm{Sr}^{2+}$ ions.

\section{Conclusions}

Titanium and strontium doped mullite composites have been synthesized by sol-gel technique, and their phase evolution and dielectric properties have been investigated. The dielectric constant decreased with frequency for all the samples attaining constancy at high frequency, which is a normal behavior for dielectric ceramics. Reported maximum dielectric constants are 24.42 and 37.6 at $1400{ }^{\circ} \mathrm{C}$ for $0.01 \mathrm{M}$ concentration for titanium and strontium ions at $2 \mathrm{MHz}$, respectively.

AC conductivity increased with frequency following Jonscher's power law and was found to depend on the amount of glassy phase and concentration of mobile ions present in the composites. The doped mullite may 

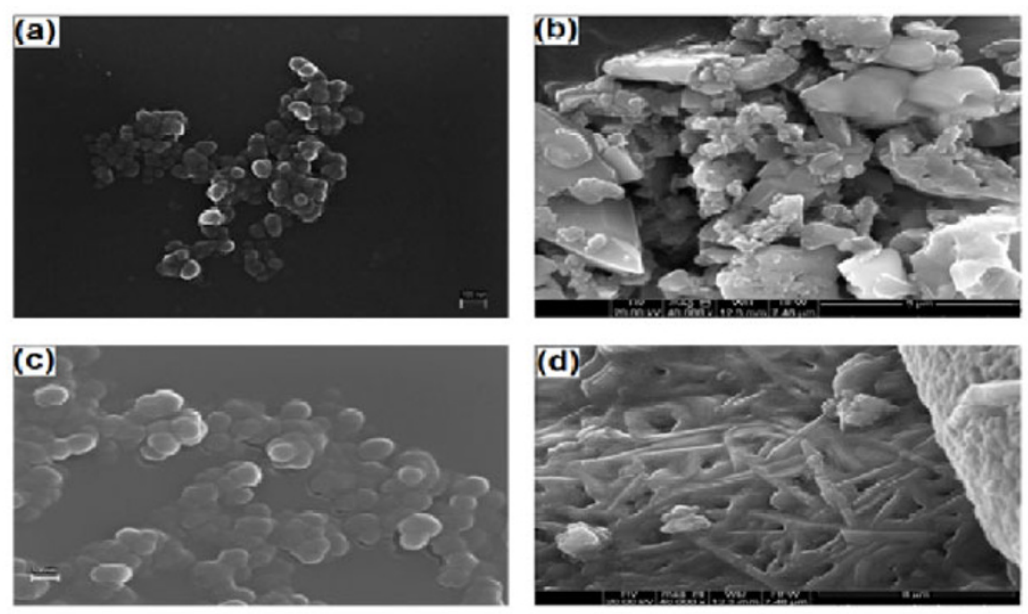

Fig. 11 SEM images of $\mathrm{G}_{3}$ samples: (a) titanium doped mullite fired at $1100{ }^{\circ} \mathrm{C}$, (b) strontium doped mullite fired at $1100{ }^{\circ} \mathrm{C}$, (c) titanium doped mullite fired at $1400{ }^{\circ} \mathrm{C}$ and (d) strontium doped mullite fired at $1400{ }^{\circ} \mathrm{C}$.

be used for the fabrication of high charge storing capacitors and also as ceramic capacitors in the pico range.

\section{Acknowledgements}

We are grateful to DST and UGC (PURSE program), Government of India, for the financial assistance.

Open Access: This article is distributed under the terms of the Creative Commons Attribution License which permits any use, distribution, and reproduction in any medium, provided the original author(s) and the source are credited.

\section{References}

[1] Maex K, Baklanov MR, Shamiryan D, et al. Low dielectric constant materials for microelectronics. $J$ Appl Phys 2003, 93: 8793.

[2] Ebadzadeh T, Lee WE. Processing-microstructureproperty relations in mullite-cordierite composites. J Eur Ceram Soc 1998, 18: 837-848.

[3] Kurihara T, Horiuchi M, Takeuchi Y, et al. Mullite ceramic substrate for thin film application. Proceedings of the 40th Electronic Components and Technology Conference, Las Vegas, NV, 1990: 68-75.

[4] Ramakrishnan V, Goo E, Roldan JM, et al. Microstructure of mullite ceramics used for substrate and packaging applications. J Mater Sci 1992, 27: 6127-6130.

[5] Viswabaskaran V, Gnanam FD, Balasubramanian M. Mullite from clay-reactive alumina for insulating substrate application. Appl Clay Sci 2004, 25: 29-35.
[6] Camerucci MA, Urretavizcaya G, Castro MS, et al. Electrical properties and thermal expansion of cordierite and cordierite-mullite materials. $J$ Eur Ceram Soc 2001, 21: 2917-2923.

[7] Kanka B, Schneider H. Sintering mechanisms and microstructural development of coprecipitated mullite. J Mater Sci 1994, 29: 1239-1249.

[8] Sanad MMS, Rashad MM, Abdel-Aal EA, et al. Synthesis and characterization of nanocrystalline mullite powders at low annealing temperature using a new technique. J Eur Ceram Soc 2012, 32: 4249-4255.

[9] Esharghawi A, Penot C, Nardou F. Contribution to porous mullite synthesis from clays by adding $\mathrm{Al}$ and Mg powders. $J$ Eur Ceram Soc 2009, 29: 31-38.

[10] Sanad MMS, Rashad MM, Abdel-Aal EA, et al. Effect of $\mathrm{Y}^{3+}, \mathrm{Gd}^{3+}$ and $\mathrm{La}^{3+}$ dopant ions on structural, optical and electrical properties of o-mullite nanoparticles. $J$ Rare Earth 2014, 32: 37-42.

[11] Sanad MMS, Rashad MM, Abdel-Aal EA, et al. Mechanical, morphological and dielectric properties of sintered mullite ceramics at two different heating rates prepared from alkaline monophasic salts. Ceram Int 2013, 39: 1547-1554.

[12] Roy DS, Bagchi BJ, Bhattacharya AN, et al. A comparative study of densification of sol-gel-derived nano-mullite due to the influence of iron, nickel and copper ions. Int J Appl Ceram Tec 2013, DOI: 10.1111/ijac.12114.

[13] Roy DS, Bagchi BJ, Das SK, et al. Electrical and dielectric properties of sol-gel derived mullite doped with transition metals. Mater Chem Phys 2013, 138: 375-383.

[14] Sanad MMS, Rashad MM, Abdel-Aal EA, et al. Optical and electrical properties of $\mathrm{Y}^{3+}$ ion 
substituted orthorhombic mullite $\mathrm{Y}_{(x)} \mathrm{Al}_{(6-x)} \mathrm{Si}_{2} \mathrm{O}_{13}$ nanoparticles. J Mater Sci: Mater Electron 2014, 25: 2487-2493.

[15] Archana J, Navaneethan M, Hayakawa $Y$. Hydrothermal growth of monodispersed rutile $\mathrm{TiO}_{2}$ nanorods and functional propertie. Mater Lett 2013, 98: $38-41$.

[16] Misevicius M, Scit O, Grigoraviciute-Puroniene I, et al. Sol-gel synthesis and investigation of un-doped and Ce-doped strontium aluminates. Ceram Int 2012, 38: $5915-5924$.

[17] Sanad MMS, Rashad MM, Abdel-Aal EA, et al. Effect of $\mathrm{Gd}^{3+}$ ion insertion on the crystal structure, photoluminescence, and dielectric properties of o-mullite nanoparticles. J Electron Mater 2014, 43: 3559-3566.

[18] Patil DR, Lokare SA, Devan RS, et al. Studies on electrical and dielectric properties of $\mathrm{Ba}_{1-x} \mathrm{Sr}_{x} \mathrm{TiO}_{3}$. Mater Chem Phys 2007, 104: 254-257.

[19] See A, Hassan J, Hashim M, et al. Dielectric variations of barium titanate additions on mullitekaolinite sample. Solid State Sci Tech 2008, 16:
197-204.

[20] Ravinder D, Mohan GR, Prankishan, et al. High frequency dielectric behavior of aluminumsubstituted lithium ferrites. Mater Lett 2000, 44: 256-260.

[21] Chakraborty AK. Role of hydrolysis water-alcohol mixture on mullitization of $\mathrm{Al}_{2} \mathrm{O}_{3}-\mathrm{SiO}_{2}$ monophasic gels. J Mater Sci 1994, 29: 6131-6138.

[22] Chakraborty AK. Effect of $\mathrm{pH}$ on $980{ }^{\circ} \mathrm{C}$ spinel phase-mullite formation of $\mathrm{Al}_{2} \mathrm{O}_{3}-\mathrm{SiO}_{2}$ gels. $J$ Mater Sci 1994, 29: 1558-1568.

[23] Zhang Y, Wu Z, Wang S, et al. Density of $\mathrm{Li}_{2} \mathrm{TiO}_{3}$ solid tritium breeding ceramic pebbles. Adv Mat Res 2011, 177: 310-313.

[24] Oréfice RL, Vasconcelos WL. Sol-gel transition and structural evolution on multicomponent gels derived from the alumina-silica system. $J$ Sol-Gel Sci Technol 1997, 9: 239-249.

[25] Roy DS, Bagchi BJ, Das SK, et al. Dielectric and magnetic properties of sol-gel derived mullite-iron nanocomposite. J Electroceram 2012, 28: 261-267. 